\title{
СОВЕРШЕНСТВОВАНИЕ МЕТОДОВ ОТРАЖЕНИЯ В ФИНАНСОВОЙ ОТЧЕТНОСТИ ОБЪЕДИНЕНИЯ БИЗНЕСОВ
}

\section{IMPROVING METHODS FOR REPORTING BUSINESS COMBINATIONS IN FINANCIAL STATEMENTS}

\section{Epifanov}

Summary: The article discusses the features of improving the methods of reflection in the financial statements of business associations. When considering the practical aspects of the merger, the methodological recommendations on the application of the international financial reporting standard (IFRS) 3 "business combination" were taken into account.

The scientific novelty of the study is expressed in the development of a methodology for checking goodwill for impairment in a business combination.

Keywords: financial reporting, business, business combination, accounting, improvement of methods.

\author{
Епифанов Иван Николаевич \\ Аспирант, Финансовый университет \\ при Правительстве РФ \\ epifanov.in@mail.ru
}

Аннотация: В статье рассматриваются особенности совершенствования методов отражения в финансовой отчетности объединения бизнесов. При рассмотрении практических аспектов объединения учитывались методические рекомендации по применению международного стандарта финансовой отчетности (IFRS) 3 «0бъединение бизнеса».

Научная новизна исследования выражается в разработке методологии проверки гудвила на обесценение при объединении бизнеса.

Ключевые слова: финансовая отчетность, бизнес, объединение компаний, учёт, совершенствование методов. од объединением бизнеса понимается операция или событие, в результате которого покупатель получил контроль над одним или несколькими бизнесами. Контроль - это возможность управлять финансовой и операционной политикой компании в целях получения выгоды от ее деятельности. Объединение бизнеса регулируется IFRS 3 «Объединение бизнеса», в соответствии с которым компании при объединении бизнеса должны применять метод приобретения: [1]

1. идентифицировать покупателя;

2. определить дату приобретения (дата, когда покупатель приобретает контроль над бизнесом;

3. признать и оценить активы, обязательства и неконтролирующую долю (к примеру, компания должна признать и оценить патент и фирменный знак, которые приобретаемая компания в своей отчетности не признавала);

4. признать и оценить гудвил и доход от выгодной покупки.

Сделки по слияниям и поглощениям, именуемые в МСФО объединениями бизнесов, играют ключевую роль в мировой экономике. Например, в 2019 году сумма объявленных сделок составила 4 трлн долл. США.

Требования к учёту таких операций устанавливает MCФO (IFRS) 3 «Объединения бизнесов» (выпущен в 2004 году, пересмотрен в 2008-м). Через 15 лет после выпуска MCФО (IFRS) целесообразно оценить, работает ли этот стандарт так, как было задумано. Такая последующая оценка называется анализом практики применения. [2]

При анализе мнений заинтересованных сторон становится очевидным, что наибольшую обеспокоенность вызывают следующие аспекты совершенствования учёта приобретения бизнеса: [3]

1. инвесторы не получают достаточной информации о приобретенных компаниях и их последующей деятельности;

2. тест на обесценение сложный и дорогостоящий;

3. убытки от обесценения гудвила признаются слишком поздно;

4. гудвил не амортизируется. Но компания оплатила его, поэтому рано или поздно он должен повлиять на прибыль или убыток;

5. компаниям трудно учитывать некоторые нематериальные активы, например отношения с клиентами и бренды, отдельно от гудвила.

В этих условиях, целесообразно проанализировать данные недостатки и предложить изменение подходов к учёту в некоторых случаях.

Инвесторы хотят получать информацию о приобретении бизнеса в момент совершения сделки и о том, насколько хорошо бизнес работает в дальнейшем. Это позволит оценить, как эффективно руководство проводит сделки по приобретению бизнеса: ставит цели, платит 
правильную цену, интегрирует приобретенный бизнес и получает выгоды от сделки.

Однако МСФО не требуют от компаний информировать о том, соответствует ли приобретение ожиданиям руководства.

Чтобы предоставить инвесторам необходимую информацию, Совету по МСФО целесообразно потребовать от компаний раскрывать цели руководства по приобретению бизнеса и то, как они достигли этих целей. Такая информация должна основываться на показателях, которые использует руководство при приобретении компаний, а не на показателях, определенных Советом по МСФО, поскольку: [3]

- Совет по МСФО исходит из того, что руководство контролирует приобретения бизнеса и осведомлено о том, насколько хорошо они осуществляются;

- цели приобретения - специфические для конкретной компании. Поэтому ни один набор показателей, определенный Советом по МСФО, не может предоставить полезную информацию обо всех приобретениях.

Таким образом, компании будут раскрывать информацию, которую менеджмент использует для мониторинга приобретений компаний. Не нужно будет получать информацию исключительно для финансовой отчетности.

В этих условиях, Совету по МСФО целесообразно рассмотреть мнения инвесторов о том, насколько полезной будет информация о последующих результатах приобретения, а также о том, обеспечит ли предложенный вариант раскрытие той информации, которая необходима инвесторам. Разработчики также просят высказаться по поводу величины затрат, связанных с выполнением новых требований к раскрытию информации.

\section{1. Методология Алительности раскрытия информашии об объединении бизнеса.}

Информация о результатах приобретения бизнеса становится неактуальной достаточно быстро.

Дело в том, что такой бизнес спустя время становится неотличимым от остальной части компании. Тем не менее руководство компании, скорее всего, будет знать о том, насколько хорошо работает приобретенный бизнес в первые несколько лет после приобретения, даже если он интегрирован.

При этом, компания должна предоставлять информацию о приобретении бизнеса до тех пор, пока ее руководитель, принимающий операционные решения, продолжает контролировать приобретенный бизнес в соответствии со своими целями.

Если руководитель, принимающий операционные решения, не контролирует приобретенный бизнес или прекращает его контролировать вскоре после приобретения, компания должна будет раскрыть этот факт и объяснить причины.

Кроме того, необходимо улучшить раскрытие информации, предоставляемой в год приобретения бизнеса. В частности, компаниям придется раскрывать информацию: [4]

- об ожидаемом синергетическом эффекте. Компании должны будут описать синергетический эффект, ожидаемый от приобретения, и раскрыть предполагаемую сумму синергетического эффекта или диапазон сумм. Эта информация поможет инвесторам лучше понять факторы, которые повлияли на цену приобретения;

- о пенсионных планах с установленными выплатами и долговых обязательствах приобретенных компаний.

Эти суммы необходимо будет представлять отдельно от других классов обязательств, что поможет инвесторам оценить рентабельность вложенного капитала.

В отношении учёта гудвила больше всего опасений пользователей отчетности вызывает то, что: [3]

- убытки от обесценения гудвила часто признаются слишком поздно, гораздо позже событий, вызвавших эти убытки;

- проверка на обесценение зачастую дорогая и сложная процедура.

С учётом этого, целесообразно рассмотреть вопросы:

а) можно ли сделать тест на обесценение более эффективным;

б) следует ли амортизировать гудвил;

в) можно ли упростить тест на обесценение.

\section{2. Методология проверки гудвила на обесшенение.}

Многие активы, например здание или бренд, могут создавать ценность для компании только путем совместной работы с другими активами. Компании проверяют эти активы на предмет обесценения совместно, как группу.

Такие группы активов называются единицами, генерирующими денежные средства (ЕГДС). Гудвил - один из таких активов, которые можно проверить на обесценение только вместе с другими активами.

Если группа активов обесценена, убыток от обесце- 
нения уменьшает сначала балансовую стоимость любого гудвила в ЕГДС, а затем балансовую стоимость других активов. В результате тест на обесценение не поможет определить, обесценился ли гудвил.

\section{3. Методология повышения эффективности теста на обесшенение.}

Тест на обесценение не позволяет своевременно выявить обесценение гудвила. Это происходит из-за того, что: [5]

- руководство компании слишком оптимистично оценивает будущие денежные потоки;

- гудвил «защищен» от обесценения, например за счет активов компании, с которыми интегрирован приобретенный бизнес (рисунок).

Запас прочности возникает из-за того, что не вся стоимость бизнеса отражается на балансе компании. Например, отчет о финансовом положении компании не включает гудвил, созданный внутри компании, разницы между балансовой стоимостью признанных активов и обязательств и их возмещаемой стоимостью.

Таким образом, получается, что существенно повысить эффективность теста на обесценение гудвила при разумных затратах не получится.

Исключить эффект «защиты» из теста на обесценение невозможно, поскольку гудвил проверяют на обесценение вместе с другими активами, которые могут содержать запас прочности.

Таким образом, тест на обесценение гудвила не всегда может сигнализировать о том, насколько хорошо работает приобретенный бизнес.
Чтобы удовлетворить потребность инвесторов в своевременной информации о результатах приобретений бизнеса, Совет по МСФО разработал дополнительные требования к раскрытию информации, указанные выше. Если тест на обесценение проводится добросовестно, можно ожидать, что он достигнет своей цели. А вопрос об оптимистичности оценки будущих денежных потоков лучше всего решать аудиторам и регулирующим органам, а не путем изменения МСФО. В соответствии с MCФО (IAS) 36 «Обесценение активов» компании обязаны использовать разумные и обоснованные оценки при проведении теста на обесценение.

\section{4. Совершенствование методологии оченки обесшенения.}

В настоящее время целесообразно изучить вопрос о том, следует ли вновь разрешить амортизацию гудвила. Всегда существовали разные мнения о том, как поступать с гудвилом: амортизировать или проверять на предмет обесценения. Каждый подход имеет свои ограничения. Не существует теста на обесценение, который мог бы непосредственно проверить гудвил. А при амортизации трудно оценить срок полезного использования гудвила и характер его уменьшения. Сейчас есть следующие аргументы в пользу обеих точек зрения (табл. 1). [4]

По предварительному мнению разработчиков, следует сохранить действующую модель обесценения. Нет убедительных доказательств того, что амортизация гудвила позволит существенно улучшить финансовую отчетность. Однако разработчики хотят изучить мнения заинтересованных сторон.

В целях совершенствования методологии отражения в финансовой отчетности объединения бизнесов целе-

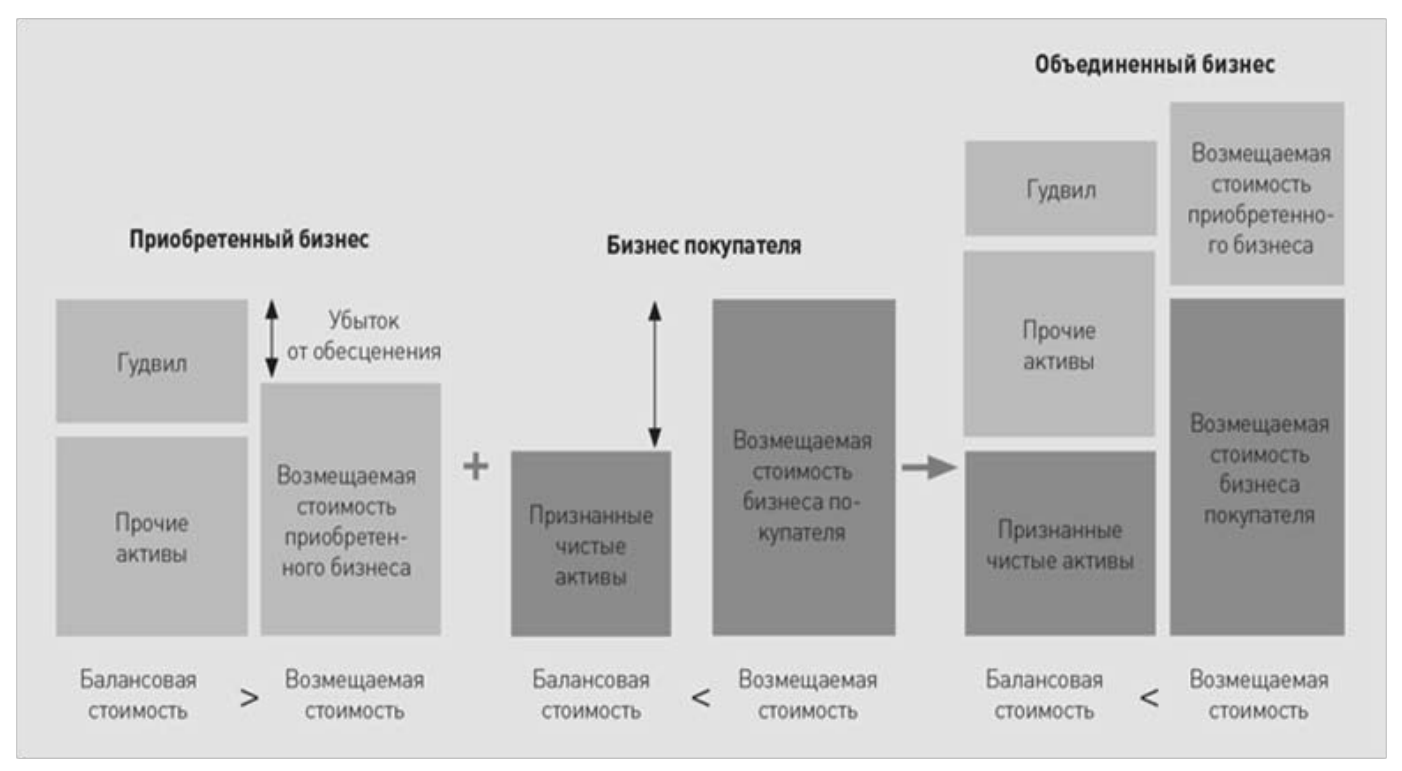

Рис. 1. Эффект «защиты» гудвила при объединении бизнеса [5] 
Таблица 1.

Аргументы в пользу амортизации и обесценения гудвила при объединении бизнеса

Аргументы в пользу амортизации гудвила

Суммы гудвила на балансе компании завышены. В результате руководство компании не привлекается к ответственности. Амортизация обеспечивает простой механизм, который нацелен на приобретенный гудвил, чего не может сделать тест на обесценение

Как показывает практика, тест на обесценение работает не так хорошо, как предполагал Совет по МСФ0. И не всегда приводит к списанию гудвила, который потерял свою ценность

Гудвил — это исчерпываемый актив, который уменьшается по мере потребления выгод. Амортизация - единственный способ показать использование гудвила

Амортизация гудвила в конечном итоге сделает тест на обесценение более легким и менее затратным для применения. Ведь амортизация уменьшит балансовую стоимость гудвила, сделав обесценение менее вероятным
Аргументы в пользу тестирования на обесценение

Модель обесценения предоставляет инвесторам полезную подтверждаемую информацию. Хотя амортизация проста, она приводит к произвольным результатам, которые будут игнорировать многие инвесторы. И многие компании исключат ее из показателей эффективности, которые они предоставляют инвесторам

При правильном применении тест на обесценение работает так, как задумал Совет по МСФ0, гарантируя, что стоимость гудвила и других активов компании не будет завышена

Преимущества гудвила сохраняются в течение неопределенного периода времени, поэтому гудвил не является исчерпываемым активом

Амортизация гудвила не приведет к существенному снижению стоимости тестирования на обесценение, особенно в первые несколько лет

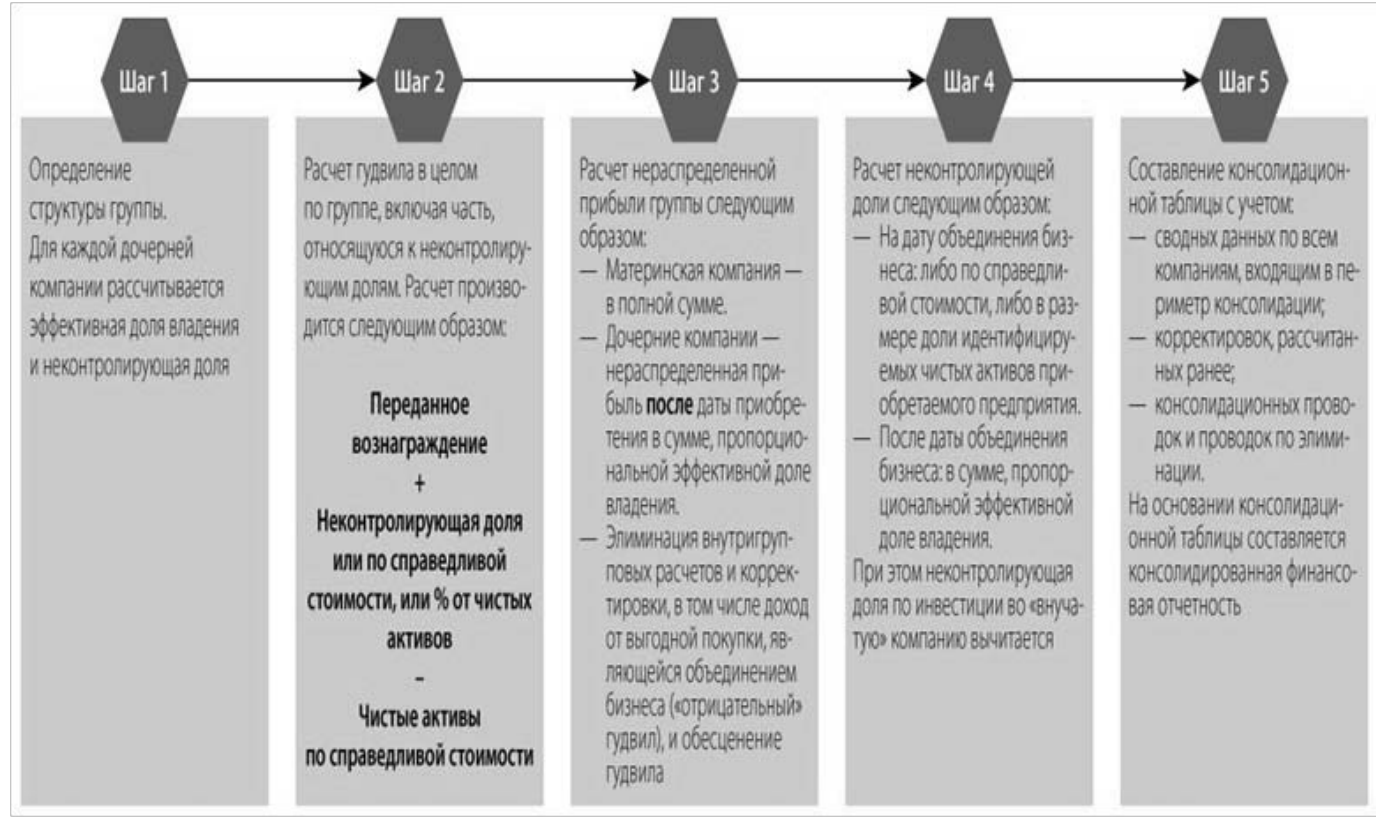

Рис. 2. Усовершенствованная схема отражения в финансовой отчетности объединения бизнесов

сообразно изменить тест на обесценение без потери надежности.

МСФО (IAS) 36 требует проводить ежегодные тесты на обесценение даже в тех случаях, когда нет оснований полагать, что обесценение могло произойти. По мнению заинтересованных сторон, ежегодный тест довольно затратен для компаний и дает мало полезной информации инвесторам, когда нет признаков обесценения. [5]

Для изменения методологии целесообразно исключить требование о проведении ежегодного количественного теста на обесценение ЕГДС, содержащих гудвил, если нет признаков обесценения. Но в конце каждого отчетного периода компаниям по-прежнему необходи- мо будет оценивать наличие признаков обесценения. При этом ожидается, что это позволит снизить затраты на проверку гудвила на обесценение. Вместе с тем, это изменение сделает тест менее надежным, поскольку: [4]

- при отсутствии признаков обесценения маловероятно, что количественный тест выявит большие убытки от обесценения;

- выполнение может исключить эффект «защиты», описанный выше.

MCФО (IAS) 36 требует, чтобы компании оценивали стоимость использования на доналоговой основе и исключали из своих прогнозов денежные потоки от будущих незавершенных реструктуризаций или улучшений активов. Это делает тест на обесценение дорогостоя- 
щим. Ставки дисконтирования до налогообложения не наблюдаются, поэтому проверка обычно проводится на постналоговой основе.

В связи с этим целесообразно: [4]

- снять ограничение на включение денежных потоков от незавершенных будущих реструктуризаций или улучшений активов. Прогнозы движения денежных средств по-прежнему должны быть разумными и обоснованными;

- разрешить использование ставок дисконтирования и денежных потоков после уплаты налогов.

Эти изменения позволят:

- снизить стоимость и сложность проведения тестов на обесценение путем согласования оценок движения денежных средств с внутренними прогнозами компаний;

- получить более полезную и понятную информацию, которая согласуется с оценками руководства и отраслевой практикой.

В рамках данного проекта целесообразно Совету по МСФО рассмотреть также вопросы, касающиеся учёта собственного капитала и приобретенных нематериальных активов в связи с гудвилом.

При этом, компании должны представлять на балансе сумму капитала без учёта гудвила.

Гудвил отличается от других активов. Например, его нельзя продать отдельно или оценить непосредственно. Представление капитала без учёта гудвила на балансе сделает эту сумму более заметной и привлечет внимание инвесторов к компаниям, гудвил которых составляет значительную часть их чистых активов. Сумма капитала без учёта гудвила может не так легко вписаться во все форматы балансового отчета в качестве промежуточного итога. Однако ее можно представить на балансе в виде отдельной строки.

В дальнейшем, Совет по МСФО планирует сохранить требования МСФО (IFRS) 3 и МСФО (IAS) 38 «Нематериальные активы». При выпуске МСФО (IFRS) 3 разработчики расширили круг приобретенных нематериальных активов, признаваемых отдельно от гудвила, например включили в него бренды. С одной стороны, отдельное признание помогает объяснить, что именно купила компания. Такой подход также гарантирует, что нематериальные активы с ограниченным сроком полезного использования признают отдельно и будут амортизировать. С другой стороны, отдельное признание не дает полезной информации, поскольку: [3]

- аналогичные нематериальные активы не признаются, если они были созданы внутри компании;

- некоторые нематериальные активы трудно идентифицировать и оценить.

Из-за различных мнений о том, насколько полезна и затратна эта информация, у разработчиков нет убедительных доказательств того, что они должны изменить список нематериальных активов, признанных при объединении бизнеса. А вопросы учёта приобретенных и внутренне созданных нематериальных активов выходят за рамки проекта.

\section{ЛИТЕРАТУРА}

1. Федеральный закон "0 консолидированной финансовой отчетности" от 27.07 .2010 N 208-Ф3 (ред. от 07.04.2020)

2. Международный стандарт финансовой отчетности (IFRS) 3 "Объединения бизнесов" (введен в действие на территории Российской Федерации Приказом Минфина России от 28.12.2015 N 217н) (ред. от 22.01.2019)

3. Григорьева С.А., Черкасова В.А (2015) Сделки слияний и поглощений и стоимость финансовых компаний на развитых европейских рынках капитала// Финансовая аналитика: проблемы и решения, №35, с. 36-49

4. Ивашковская И.В. (2019) Влияние корпоративного управления на стратегическую эффективность компании в России//Корпоративное управление, №48, c. $21-28$

5. Ивашковская И.В., Солнцева М.С. (2019) Детерминанты стратегических решений о финансировании крупных компаний на развивающихся рынках капитала: пример России, Бразилии и Китая// Российский журнал менеджмента, Том 7, № 1, с. 25-42 